\title{
Mental Health in a Social Context
}

\section{Byron Kiiza Yafesi Bitanihirwe}

Systems and Cell Biology of Neuro degeneration, University of Zürich, Switzerland

${ }^{*}$ Corresponding author: Byron Kiiza Yafesi Bitanihirwe, Systems and Cell Biology of Neuro-degeneration, University of Zürich, Switzerland, Tel: 41446341111; E-mail: b.bitanihirwe@gmail.com

Received Date: January 2, 2014, Accepted Date: September 23, 2014, Published Date: September 30, 2014

Copyright: (c) 2014 Byron Kiiza Yafesi Bitanihirwe, This is an open-access article distributed under the terms of the Creative Commons Attribution License, which permits unrestricted use, distribution, and reproduction in any medium, provided the original author and source are credited.

\begin{abstract}
Mental illness remains a scourge of modern day society and results in a substantial burden of disease worldwide. The demographic effects of mental illness are evident across the human life span in both women and men (girls and boys), among all ethno-cultural, racial groups and people of different socioeconomic status. In addition to being responsible for immense suffering, poor quality of life and increased mortality, mental illness results in significant economic and social costs. Groups experiencing adverse life circumstances and less economic resources often exhibit an increased susceptibility to mental illness. The vulnerability among people with mental illness renders them susceptible to human rights violation and abuse. Although these problems have received increasingly widespread recognition by international agencies and governments, the necessary policies and resources to improve mental healthcare remain overlooked around the world. This review articulates the importance of mental health and touches on policies in addition to potential means for assisting people with mental illness better integrate into society. Because mental health is essential to achieving prosperity, investment of finance and human resources within this area will not only result in increased economic gain but will help people with mental illness live a more just and dignified life.
\end{abstract}

Keywords: Mental illness; Stigma; Public health; Mental healthcare; Low and middle income countries

\section{Introduction}

Mental health remains a controversial topic with outmoded prejudices and stereotypes often making people affected by mental illness a 'taboo' subject. Despite the significant challenge of trying to understand the intrinsic relationship between the brain and the mind, neuroscientists have made tremendous strides in piecing together the molecular and genetic complexities governing the cognitive underpinnings of brain function and its infirmities [1]. Nonetheless, myths and stigma still persist in parts of the world regarding patients who are affected by severe mental illnesses such as schizophrenia and affective psychotic disorders [2-4]. Besides reducing the patients' access to resources and opportunities (e.g. housing, education, employment and healthcare), mental illness can deprive people of their dignity (e.g. involuntary confinement without fair process) and may ultimately interfere with their full participation in society [5-7].

The landmark publication by the US Department of Health and Human Services in 1999 entitled: "Mental health: A report of the Surgeon General "called for a broad public health approach to mental health and mental illness. A general precept of this document is that the surveillance and research of mental health should be promoted with an equivalent importance on the clinical diagnosis and treatment of mental illness [8]. In addition, this report calls to attention the notion that mental health and mental illness are not polar opposites and in fact maybe considered as points on a continuum (Figure 1) [8].

\section{Negative Life events \\ Mental Health Adverse life occurrences, low self esteem, etc... Positive Life events Mental IIIness}

Supportive relationships, High self esteem, etc...

Figure 1: Mental Health as a Continuum

Mental health has been defined as "a state of well-being enabling individuals to realize their abilities, cope with the normal stresses of life, work productively and fruitfully, and make a contribution to their communities" by the World Health Organization (WHO) [9]. Reference to this definition makes it clear that mental or psychological well-being is influenced not only by individual characteristics or attributes, but also by the socioeconomic circumstances in which persons find themselves and the broader environment in which they live (Figure 2). 


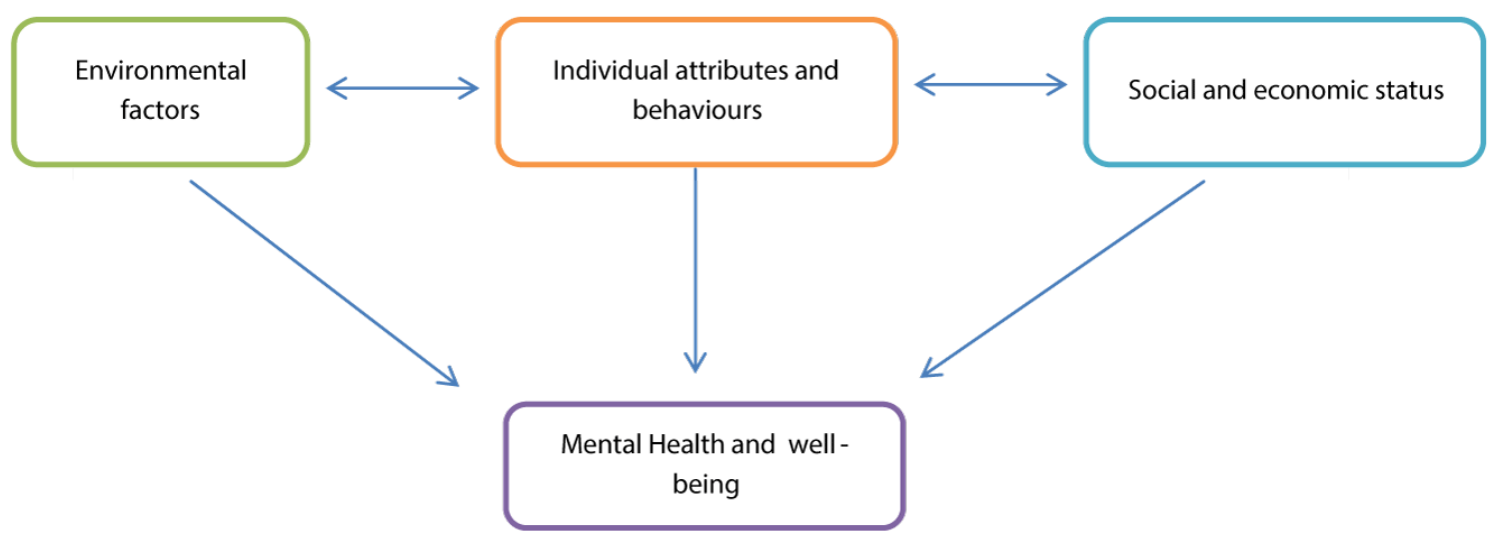

Figure 2: Contributing factors to mental health and well-being (Adapted from [10])

Although the WHO's popular definition of health conceived in the aftermath of the second world war gives physical and mental health equal emphasis [11] mental health has never quite enjoyed the attention devoted to physical health problems on international public health agendas. The literature however identifies the clear existence of a complex and inextricable link between mental health and physical health [12]. Besides correlating with physical activity and health risk behaviors (such as smoking, alcohol consumption and sexual promiscuity), mental illness has also been shown to influence the onset, progression, and outcome of other illnesses with a subsequent negative impact on life expectancy [13-15], For instance, depression has emerged as a risk factor for cardiovascular disease [16] and cancer [17].

Despite their vulnerability, people with mental illness have been overlooked by development programmers [18]. The main reasons surrounding this problem include the prevailing public health priority agenda and its effect on funding, lack of financial and human resources in addition to a lack of adequate mental healthcare law in many countries [19-23]. As a means to tackle and address these issues, the WHO recently launched the Mental Health Action Plan 2013-2020 [24]. This report recognizes and emphasizes the essential role of mental health in achieving health for all people.

Against this background, the current review aims to provide the reader with an overview of the magnitude and burden associated with mental illness. In addition, it discusses potential means and tools which may facilitate the assessment and treatment of people affected by these health conditions, with a particular focus on low and middle income countries (LAMICs). Moreover, it touches on potential methods for people with mental disorders better integrate in to society. The benefits associated with investing in mental healthcare services (i.e. financial and human resources) and in attempting to shift people's perceptions of mental illness will ultimately result in a better quality of life and health for the individuals and communities but also result in greater financial returns to society at large from increased productivity and lower net costs of illness and care.

\section{The Global Burden of Mental Illness}

Mental health disorders are common with one person in four developing some kind of mental health problem during their lifetime
[21]. The current literature suggests that mental health conditions account for approximately $13 \%$ of the global burden of disease (GBD) [25], and this figure has been predicted to rise to nearly $15 \%$ by 2020 [26]. Besides the significant impact on GBD, the economic costs wrought by mental and neurological disorders are significant, mainly stemming from output losses and the healthcare costs of treating these conditions.

The Global Burden of Disease report first published in 1993 by the WHO in conjunction with the World Bank and the Harvard School of Public Health has become the benchmark as a means to assess, and compare, the mortality and disability posed by various diseases, injuries and risk factors in each region of the world. The methods and findings of this report have been widely published [28-31]. Specifically, the GBD study uses a measure called disability adjusted life years, or DALYs, to assess the overall burden of disease, expressed as the number of years lost due to ill-health, disability or premature mortality:

\section{$\mathrm{DALY}=\mathrm{YLL}+\mathrm{YLD}$}

Where: YLL = Years of life lost due to premature mortality. YLD = Years lived with disability

As an example, the psychosis associated with schizophrenia produces disability equivalent to quadriplegia whereas the disability caused by major depression is equivalent to blindness or paraplegia. 32This section focuses on the prevalence and economic costs attributable to mental illness.

\section{Prevalence of Mental Illness}

Mental illness has been estimated to affect around 450 million people worldwide [21] yet despite this substantial figure many patients still feel ashamed to seek diagnosis and support. Considering the 'ripple effect' resulting from the impact of mental illness on family, friends and community it is probable that an even higher number of people may be affected directly or indirectly by neuropsychiatric conditions. Although mental illness is prevalent in all population groups it appears to occur more frequently in vulnerable groups including populations afflicted by poverty, older adults, children and other disempowered groups $[6,18]$. 
It has been estimated that the prevalence and burden of mental disorders will grow in the coming decades. Low and middle income countries with poorly developed mental healthcare systems are likely to see the most substantial increases in the burden attributable to mental disorders. Despite the impressive reduction in rates of infant mortality and infectious diseases in LAMICs the end result is a greater number of people reaching the age of vulnerability for mental disorders with a notable example being dementia. In this regard, the recent report entitled: "Dementia: a public health priority" developed jointly by the WHO and Alzheimer's Disease International, provides compelling data on the enormity of the current and future challenges and stresses the need for action to avert a dementia-related crisis, with a particular emphasis in LAMICs [27].

According to the 2010 GBD report mental and substance use disorders are the leading global cause $(22.9 \%)$ of all non-fatal years lived with disability [33] above both cancer $(0.6 \%)$ in addition to cardiovascular and circulatory disease $(2.8 \%)$. It is also important to note that intentional injuries and human immunodeficiency virus infection (HIV)/acquired immunodeficiency syndrome (AIDS) which also made the list have been shown to have a behavioral component linked to mental health. In the context of intentional injuries, suicidal behavior while not in itself a mental illness, has been highly correlated with mental illness [34-36].While the relation between suicide and mental illness is complex, it is thought that suicidal ideation in people with mental illness may stem from these patients dealing with the symptoms of their illness in addition to difficult life circumstances [34,37]. Approximately $85 \%$ of suicides in the world have been reported to occur in LAMICs $[38,39]$. Given the unreliability of official statistics in LAMICs these figures may substantially underestimate the true incidence of suicide in these regions.

Mental disorders are also risk factors for other health conditions, for instance through the contribution of alcohol abuse to liver disease. Harmful drinking has been shown to contribute a significant proportion of the burden of disease as determined by un intentional and intentional injuries, including those due to road traffic accidents, and suicides. Just as significant is the fact that people with chronic physical disease have much higher rates of mental illness than the general population [17]. For example, studies have reported people living with HIV/AIDS are at an increased risk of developing serious mental disorders (including HIV encephalopathy, psychosis, depression, mania, cognitive disorder, and frank dementia, often in combination) $[40,41]$. Indeed, research suggests that infants and children with HIV infection are more likely to experience deficits in motor and cognitive development compared with HIV negative children [42]. The presence of mental health conditions interlinked with HIV/AIDS can compromise adherence to HIV medication and secondary prevention efforts [43] key requirements for successful management of HIV/AIDS and which subsequently contribute to the global burden of the disease [44].

\section{Economic Impact}

Besides affecting the individual and their families' economic welfare, mental and neurological disorders also place considerable strain on the general economy. The societal costs of mental disorders on the social welfare and the criminal justice systems are a significant issue. Indeed, a recent report from the World Economic Forum estimated the costs associated with mental illness of US\$ 2.5 trillion for the year 2010, with the cost projected to surge to US $\$ 6$ trillion by 2030 [45]. What is more, in ministries of health across the world and in influential international bodies such as the WHO and the World Bank it is now accepted that mental health well-being is strongly related to many economic development sectors (e.g. employment, law enforcement, education, and incarceration) [46] and several Millennium Development Goals [47] (e.g. reducing child mortality, improving maternal health, eradicating extreme poverty and hunger) [46].

The impact of mental illness on the economy is several fold including effects on labor market participation, productivity and earnings [48]. For instance, in the USA costs associated with mental disorders has been estimated to be as high as US $\$ 317$ billion per year [49]. Of this total $61 \%$ is due to lost earnings amongst mentally ill people with any earnings. The remaining 39\% are due to direct healthcare costs and disability benefits. In contrast, the economic burden associated with mental illness and their societal costs in Canada has been estimated at CAD $\$ 51$ billion, with depression and schizophrenia accounting for about CAD $\$ 5$ billion and CAD $\$ 2.7$ billion annually, respectively [50]. Costs associated with mental illness in the Member States of the European Union have been estimated at $€ 798$ billion annually of which $60 \%$ is attributable to direct costs and $40 \%$ to lost productivity [51]. Indeed, the annual expenditure on mental ill 52]. In Australia the annual cost of mental illness has been estimated at AUD $\$ 20$ billion in terms of treatment costs and lost productivity [53], with schizophrenia and bipolar disorder accounting for AUD $\$ 1.85$ billion and AUD $\$ 1.59$ billion, respectively. Even though data assessing the economic costs of mental illness and mental health resources in LAMICs does exist (i.e. the WHO Mental Health Atlas study), non-response [54] or lack of relevant information [55] in such surveys provides a significant hurdle in terms of obtaining a more realistic picture of the toll of mental illness in these regions of the world.

\section{The Treatment Gap in Mental Healthcare}

With the continual advancement of modern day medicine an array of medication and psychological interventions have been developed to tackle mental illness. However, the current state of mental healthcare in LAMICs raises questions not only about the adequacy and distribution of resources for treating and preventing disorders, but also about the efficiency with which the resources are used. Against this background, it has been proposed that making interventions to tackle neuropsychiatric conditions more widely available in these regions would be cost-effective as the savings that are achieved when someone recovers from a mental health problem far outweigh the cost of providing treatment [56-58].

Despite the increased awareness of the need for treatment of people afflicted with mental illness, a substantial portion of people with diagnosed mental disorders do not receive treatment [59]. This socalled "treatment gap" is estimated to affect about $76-85 \%$ of patients with mental illness in LAMICs, as compared to $35-50 \%$ of cases with mental illness in high-income countries [60]. This is an issue for concern as mental health conditions, especially mood disorders (e.g. depression and bipolar disorder), are a significant contributor to mortality, with suicide perennially representing one of the leading causes of death.61In order to close the gap between resources and the need for treatment of mental disorders, the WHO has created the Mental Health Global Action Programme intervention guide (mhGAP IG) as part of a major effort for the scaling up of services for mental, neurological, and substance use disorders, particularly in resourceconstrained settings and countries $[60,62]$.This programme is 
specifically based on implementing strategic paradigm shifts aimed at improving the mental health of populations. 63These paradigms are designed within a framework of activities which includes support to countries in formulating policies, monitoring their mental health systems, improving legislation and reorganizing their services. Although the mhGAP's success will need to be judged over the long term (viz. via both donors' support and effective planning at the national level), the recent translation and implementation of the mhGAP for treating Syrian refugees in the Kurdistan region in addition to the "Training of Trainers" and the development of a pool of master trainers to roll out training and build up capacities of nonspecialists in Somalia and Libya, confirm the efficacy of the mhGAP IG. Notably, countries afflicted by civil unrest such as Iraq, Pakistan, Afghanistan and Egypt have also recently developed plans for mhGAP implementation. It will therefore be of importance to ascertain the effectiveness of the mhGAP IG in these countries over the long term.

\section{Social Isolation: The Effects of Stigma and Discrimination}

The life opportunities of people with mental illness are greatly limited by the stigma of these conditions often leading others to avoid living, socializing or employing people with mental disorders [3,4,64]. The Surgeon General's Report on Mental Health called stigma "powerful and pervasive" [8]. In making sense of different stigmatized groups Erving Goffman distinguished discredited groups (those who suffer stigma because of a relatively observable trait like skin color or ethnicity) from discreditable (being able to hide the stigma because the trait is not readily observable like homosexuality and many mental illnesses) [65]. It is important to state at this point that stigma not only affects people afflicted by mental illness but their families and friends as well. 64 This form of stigma is often termed "courtesy stigma" [65].

Because of the humiliation, shame and damage to the affected individual's sense of self, stigma results in poor adherence to treatment in addition to a lower likelihood of mental health service utilization [67]. Provided with this picture it is perhaps unsurprising that people with the ability to hide discreditable stigma such as mental illness need to make the careful decision of whether, where, and with whom they might disclose such information [3].

With neither medical treatment nor a clear medical explication as to the aetiology of mental illness, sorcery or black magic (i.e. the 'sick' person has been punished [by ---] or has been afflicted by a curse/evil spirits) may represent a causal explanation for these conditions in several cultures [68-70]. Within some LAMICs it has been reported that not only physicians in training but also qualified licensed physicians that have undergone psychiatric training may still hold such beliefs [71]. For example, Aghukwa reported that $23-40 \%$ of Nigerian medical students endorsed supernatural causes of mental illness, such as charms, witchcraft and evil spirits[72].Such beliefs not only increase stigma, discrimination, and social isolation towards people afflicted by mental illness but they also limit resources for their care [73].

\section{Socioeconomic Inequality and Unmet Mental Health Needs}

Because the health systems in LAMICs lack the necessary capacity for effective treatment, mental disorders are often seen as incurable. As mental illness results in loss of productivity, patients suffering from such conditions are undervalued and perceived as not able to contribute to society. In particular, health systems in LAMICs are characterized by an inequality in the distribution and allocation of mental healthcare resources [56, 78-80]. According to the WHO, health inequalities can be defined as 'differences in health status or in the distribution of health determinants between different population groups' [81]. A complex series of problems affect people confronted by unmet mental and behavioral healthcare, including continued unnecessary suffering and premature deaths, work instability, limited or lack of treatment for people suffering from these conditions, substance abuse and poverty [82]. These problems are likely to result in an increased level of incarceration and political instability. Indeed, in many LAMICs these social problems are further compounded by corruption, poor governance, social morbidity due to natural and manmade disasters (e.g. wars), which have been shown to erode social cohesion and capital, limit economic growth and serve as prognosticators of mental health problems $[48,82,83]$.

Inequity in mental health services and access to mental health professionals has been shown to occur according to various factors including but not limited to race, sexual orientation, socio-economic status and geographical region (rural/urban) [84]. In particular, disparities in mental healthcare services are commonly reported in rural as opposed to urban areas [84]. These barriers revolve around issues of availability and accessibility. In many rural communities, mental health services are not available. These include a shortage or even lack of practicing psychiatrists, psychologists, nurses, or social workers. This scarcity of trained mental health professionals means that individuals who need emergency care must commute out of their communities to other locations where care is available. But even when care is available in a given administrative district, still other barriers prevent individuals from accessing this care including a lack or unavailability of public transport in rural areas hindering access to the necessary healthcare services. Perhaps the most pervasive factor limiting access to mental healthcare services in rural areas is the lack of affordable, attainable health financing systems. Compounding these problems further is the migration of qualified mental health specialists from rural to the urban areas. Indeed, due to increased job and income opportunities associated with the urban labour market there is often an internal migration of mental healthcare workers from rural poorer communities to more wealthier urban communities [85]. In a similar vein, there is strong evidence supporting an increased influx of health workers from developing to developed nations [86]. The end result is not only a shortage of mental healthcare workers but a barrier to accessing the necessary care for many general health service consumers. Because of the limited availability of mental healthcare services in LAMICs and in some communities in developed countries, traditional and faith healers provide a valued mental health service for patients afflicted by mental disorders [87,88]. Even though traditional and faith healers oppose the tenets of Western medicine by lacking the necessary training and skills to provide effective medical care/ treatment for people with serious mental illness, they find themselves shouldering a large burden of care of patients with mental health problems $[89,80]$.

Growing international evidence has shown a close relationship to exist between poverty (or financial strain) and the development of mental illnesss [91-94]. Notably, poverty plays a crucial role in creating high levels of personal (hunger) and economic stress (e.g. debt, unemployment and lack of affordable housing) and subsequent mental ill health [91,95]. Conversely, people living with mental illness are more likely to live in poverty [95].This effect possibly stems from patients with mental illness facing greater barriers to securing 
Page 5 of 11

education and employment due to the influence of the mental disease on cognitive functionality [92]. As a result, mental illness can seriously interrupt a person's education or career path and result in diminished opportunities for employment or a lack of secure employment, in turn, affecting one's ability to earn an adequate income. As a result, people may eventually drift into poverty (Figure 3) [96].

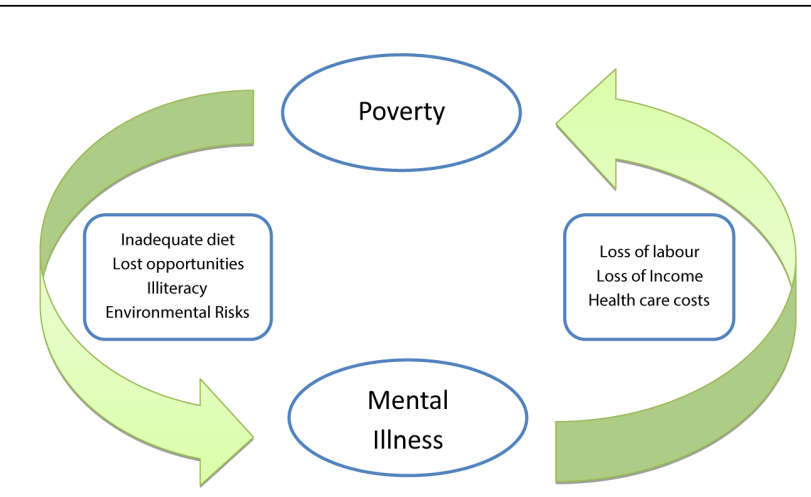

Figure 3: Two-way connection between poverty and mental illness

\section{Ethno cultural Communities and Mental Health}

The study of mental health in ethno cultural communities (viz. "a group sharing cultural features different from those of larger society, including a shared language or dialect") addresses issues of core theoretical and empirical concern to the discipline of sociology [97]. Besides exploring dominant contemporary concepts of mental health and their effect on social relationships [98] this subject area also focuses on improving pathways in to mental healthcare for ethnic minority groups afflicted by mental and psychosocial disabilities [99]. With this in mind, it is perhaps unsurprising that culture plays a significant role in shaping the experience and expression of emotional distress and social problems. There for, in order to accurately diagnose and treat patients from diverse backgrounds it is of key importance to consider the cultural meaning of symptoms and explore the social context of distress [100].In this regard, it has been shown that ethnic groups have different balances of risk factors and different rates of mental health problems $[101,102]$.

Besides the evidence suggesting that ethnic minority groups are at an increased risk of developing mental health problems [97], a perturbing issue is that many of the health promotion initiatives created for the general population often do not work for ethno cultural communities [103]. The underutilization of mental healthcare services by ethnic communities has been a growing concern in research and clinical practice as the population of immigrants to the developed world continues to rise rapidly. In this context, immigrant displacement due to factors such as political instability, better job opportunities/careers, war and natural disasters generally requires major adaptations, as people need to redefine personal, interpersonal, socioeconomic, cultural, and geographic boundaries[104].The end result is a redefinition of individual, familiar, group, and collective identities and may represent an upheaval and a source of stress for the individual, the family and the communities involved [105].

Based on these observations, several countries including the UK, US, Canada, Australia and New Zealand have conducted extensive research on the health and mental health of ethnic minority communities. The consensus is that poor access to mental healthcare can be associated with an increased utilization of the police and prison justice system, increased use of crisis and emergency care, increased hospitalization (involuntary), poorer outcomes, and an increased community burden of mental illness [99]. The picture is however complex and dependent on context. For instance, the reception of the host population, the reasons for migration and the structure of the health system in the host country represent a few of the intersecting variables which may play an integral role and make importing ideas and practice from other countries difficult [99].

Besides socioeconomic factors, a variety of cultural variables may contribute to the underutilization of mental health services, such as perceptions of mental illness, spirituality, cultural commitment, and language proficiency [106-109]. Psychotherapeutic challenges associated with client-therapist interaction and assessment and therapy techniques also serve as barriers [110]. In order to improve the effectiveness and accessibility of mental health services for ethno cultural communities, efforts to reduce the existing socioeconomic, cultural, and psychotherapeutic barriers are therefore needed $[103,110]$.

A variety of clinical considerations have been put forward as a means to improving the delivery of mental health services to ethno cultural communities including the incorporation of trans cultural nursing into nursing curricula. Besides addressing the practical challenges associated with the costs and access of mental healthcare services, improving the dissemination of information about the relevant services will remain a key priority. In addition, efforts are still necessary in order to better educate mental health practitioners, as well as physicians, nurses and clergy, on the issues, challenges, and culturally sensitive approaches. What is more, the facilitation of clienttherapist verbal communicative skills, language barriers must also be reduced. The cultural sensitivity and appropriateness of assessment and treatment procedures, and client participation in these services, must be improved. Although the empirical and clinical literature examining these issues has grown slowly but steadily, there still remain many issues to be addressed and services to be developed and provided $[103,110]$.

\section{Lessons Learned and the Way Forward}

Unfortunately people with mental illness remain neglected and marginalized strata of society. As such their potential to contribute to the community remains an undermined and untapped resource. The current section focuses on expounding on potential means and policies that could be of importance to help people afflicted by mental illness better integrate and contribute to society at large.

\section{Access to Education}

Education (viz. formal and informal education, literacy programs, basic education, vocational training, physical education and sport, social education, higher education) can help provide key life skills and opportunities to people with mental and psychosocial disabilities. The possession of such pivotal skills will help this important starta of society navigate through life's challenges with confidence and optimism. As a tool for empowerment and social development, education may help alleviate the necessity of guardianship. Importantly, education reduces the risk of exploitation and is paramount to achieving the full development of the whole person. In this respect, education plays a significant role in the employment, 
rehabilitation and reintegration of patients with mental illness. The right to education as drafted in 1948 under Article 26 of the Universal Declaration of Human Rights states [111] that:

Everyone has the right to education. Education shall be free, at least in the elementary and fundamental stages. Elementary education shall be compulsory. Technical and professional education shall be made generally available and higher education shall be equally accessible to all on the basis of merit.

Education shall be directed to the full development of the human personality and to the strengthening of respect for human rights and fundamental freedoms. It shall promote understanding, tolerance and friendship among all nations, racial or religious groups, and shall further the activities of the United Nations for the maintenance of peace.

Parents have a prior right to choose the kind of education that shall be given to their children.

The benefits of education are clear. Not only will it empower people with mental disorders but it will render them less vulnerable to violation and human rights abuses. Perhaps more importantly as alluded to by the WHO definition of mental health, education will allow for people with mental illness to develop the vital skills to gain independence via employment and in the process contribute to his or her community.

\section{Dealing with Public Stigma}

Considerable effort has been undertaken to overcome stigma. The recent Mental Health Action Plan 2013-2030 calls for change in the attitudes that perpetuate stigma and discrimination. This report emphasizes the need for the inclusion of promoting community-based multi-level interventions, involving public awareness campaigns and efforts to make mental health an integral part of public health [24].

The need to increase awareness and education regarding mental illness including the launch of educational campaigns (e.g. the National Alliance on Medical Illness has advocated for an understanding of mental illness as a biological process: "a disease like any other"), informational websites, mental illness-friendly communities and the necessity to monitor public attitudes are all of core importance. It will also be necessary to look at funding programs, such as leisure activities that recognize the retained abilities of people with mental health disorders. Such forms of intervention will help decrease the social distance from people with mental illness (Figure 4). Implementation of mental health services at the community level, such that multidisciplinary facilities for both mental and physical health are available within the same setting will provide yet another means of combatting stigma $[18,74]$.

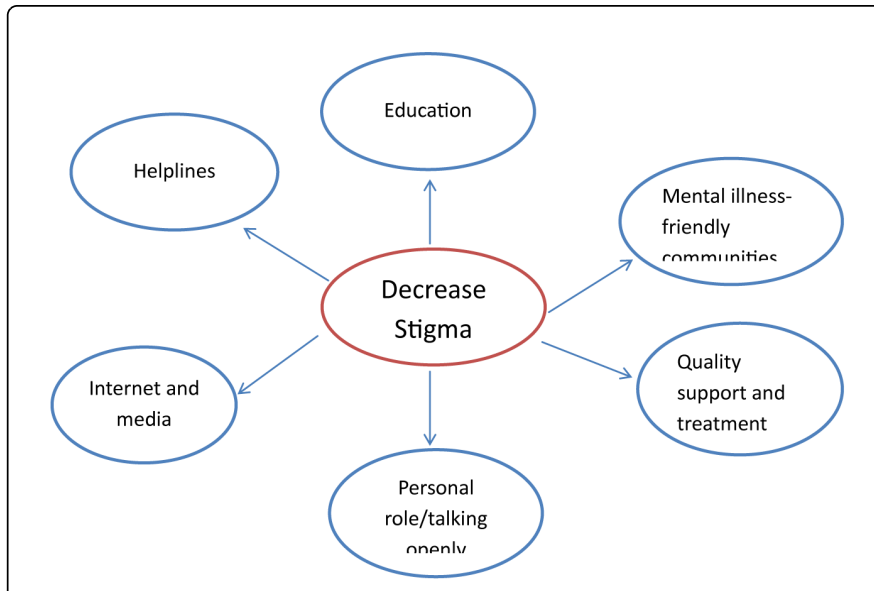

Figure 4: Strategies to combat stigma towards mental illness

\section{Access to Mental Healthcare Services}

Access to mental healthcare for people afflicted by mental illness remains a significant problem around the world despite the enormous social and economic burden on families and communities. Perhaps surprisingly, the majority of people with mental health conditions severe enough to impair their functioning are not receiving any treatment [58]. This problem has been attributed to a combination of factors such as healthcare provider issues (including the pervasive stigma associated with mental illness and lack of resources) and the separation of mental healthcare services from primary healthcare services. Against this background, there has been intense lobbying from international organizations and agencies for the integration of mental healthcare into the existing primary healthcare as a means of providing both holistic services and easier access to effective mental health treatment as advocated by the Alma Ata Declaration [112]. However, in many countries psychiatric institutions are the only form of mental healthcare available to the general population. Because these facilities are often located in major towns and cities, a long way from where people live, patients with mental health needs may have to travel great distances to seek the care they need. Besides denying many individuals access to mental healthcare due to the elevated transportation costs, another important factor includes having to take time off work to travel long distances to urban areas. What is more, in cases where people do seek treatment in psychiatric facilities, they often find themselves isolated as a result of being placed many miles from their family and their emotional and social support networks $[22,113]$. Consequently these patients are no longer able to maintain their daily living activities such as sustained employment which subsequently compromises the family's economic status. Together, these factors influence mental healthcare access, affordability and/or quality, and demonstrate that mental health service is an area of substantial unmet need.

The integration of mental healthcare in a primary care setting would allow people with mental illness easy access to treatment and care within close proximity of their homes as well as help keep families together $[22,113,114]$. It would also allow the patients to maintain their support systems, remain integrated and active in the community and continue to contribute to household productivity $[22,115,116]$ Furthermore, because primary care facilities tend be located in 
communities, not only do they serve as the first point of referral but they also help minimize a variety of indirect health expenditures associated with seeking care located further away (such as productivity loss due to the time spent in accompanying the patient to hospital and in eliminating costly trips to facilities located in urban areas), making primary healthcare universally accessible to individuals and families in the community and at a cost that the patient, community an country can afford.

The benefits associated with the integrating of mental health into primary care are significant [22,114-116], Besides providing key steps in reducing the social stigma and discrimination attached to mental ill health by tackling the social isolation, neglect, and institutionalization often associated with these health conditions, it also ensures that the population as a whole has access to the mental healthcare that they need early in the course of disorders and without disruption. In addition, treatment within a primary healthcare setting would provide for more affordable and cost-effective treatment coupled to better health outcomes. Adopting a community support approach would also allow for an increased level of social integration experienced by the patients with mental illness and as such assist in protecting their human rights $[114,116]$.

\section{Innovative Support Facilities: E-Health}

Unfortunately the establishment of universal and accessible healthcare systems in LAMICs continues to face considerable challenges. Therefore, policy-makers, donors and programme implementers have been searching for innovative means and methods to eliminate the geographic and financial barriers to health. This has resulted in an increasing interest in the potential of e-health (the use of information and communications technologies for health) and $\mathrm{m}$ health (the use of mobile technology for health, a subset of e-health) in LAMICs. In this context, internet offers opportunities for improving access to support and therapy for people with mental illness. The use of online therapy (viz. e-Therapy) and self-help programs for a variety of mental health conditions (e.g. depression, dementia, substance abuse and anxiety disorder) has been emerging in many countries [117]. These programs offer several advantages including: they are available round the clock, don't require waiting or travel time, are user-friendly, are anonymous and free of cost. The use of the internet has proved a particularly effective means of appealing to traditionally difficult to reach demographic groups including young people and women [118]. Notably, it has been reported that patients as well as therapists experience a positive relationship during e-Therapy, suggesting that it is possible to form a meaningful relationship based on written e-mail messages [119].

The rapid advances in mobile technologies and applications as well as the continued growth in coverage of mobile cellular networks have resulted in a rise in new opportunities for the integration of mobile health into existing e-Health services [120]. Indeed, the International Telecommunication Union (ITU) reports that there are now over 5 billion wireless subscribers; over $70 \%$ of them reside in LAMICs. Considering that mobile phone networks in many LAMICs surpasses internet deployment and that this facility not only offers simple interface for technology users but also provides voice operability, cellular connectivity, and relative affordability [120]. It is perhaps understandable why $\mathrm{m}$-Health may represent the most effective eHealth medium for dealing with mental health conditions in these regions of the world. On the basis of the promising evidence regarding the effective use of $\mathrm{m}$-Health to combat the spread of HIV/AIDS and increase education and awareness in LAMICs [121]m-Health technology holds the potential for improving access and transforming quality of care for people facing mental illness and addiction disorders in such similar regions of the world. Indeed, in Ghana it is now possible to have a mobile-based tele-psychiatry platform that can support community-based clinical care including e-prescriptions, laboratory and radiological investigations [122].

In keeping with this theme the recent concept of cloud computing has rapidly been emerging as a key tool in the healthcare system. Indeed, a recent survey of cloud computing adoption in healthcare provider organizations by HIMSS Analytics found that $83 \%$ of IT executives report they are using cloud services today, with "software as a service" (SaaS)-based applications being the most popular (66.9\%) [123]. Notably, this platform offers several key benefits including remote access, lower upfront costs, and reduced IT burden.

\section{Effective Mental Healthcare Services and Systems}

To help address the issues of inadequate service provision, the WHO has developed the Assessment Instrument for Mental Health Systems or WHO-AIMS as a means to systematically collect and assess essential information on the mental health system of a country or region. The goal of collecting this information is to improve mental health systems and to provide a baseline for monitoring the change. [124] On the basis of this information, treatment and prevention packages for LAMICs have been developed [125-128]. Across six World Bank regions including sub-Saharan Africa and south Asia, it is estimated that a fully scaled-up package of cost effective interventions could be implemented at a cost of around \$3-4 per person [129]. At the national level a selected package for treatment of depression, schizophrenia, epilepsy and alcohol abuse in Nigeria was estimated to cost 80 Naira per capita (less than one US dollar) [130]. Nevertheless, numerous challenges to implementation exist, especially in LAMICs. The commitment by governments and international agencies to build up the technical capacity of countries so that evidence-based treatment and prevention packages can be implemented will be of core importance [19] Governments will also need to commit to creating, reviewing and developing mental health policies, legislation and plans; and developing and disseminating advocacy and policy resources $[18,131,132]$

The identification of the most effective ways to deliver sustainable mental health services to patients in need remains an important area that requires research [131] Because of the comorbidity of mental disorders with chronic health conditions that are also increasing in burden (e.g., cardiovascular disease and diabetes) [133,134] screening and effective interventions for mental disorders will need to form an essential component of healthcare systems [134] Unfortunately, much of the burden of mental illness is not avertable at present even with optimum treatment and population coverage, 136 emphasizing the need for more research so we can better understand causes of the burden and develop better treatments.

\section{Conclusion}

Many people with mental illness, as well as their families and caregivers, experience the consequences of vulnerability on a daily basis. If unable to receive the necessary treatment and care they require, people afflicted by mental illness risk becoming marginalized by society. Although their vulnerability is not inevitable, but rather brought about by their social environments, over time it leads to a 
range of adverse outcomes, including poverty, poor health and premature death.

Mental healthcare remains an area fraught with health agenda problems, a lack of human resources and an inadequate policy framework [134]. Health reform agendas in the developed and developing world are therefore imperative in order to provide legal protection, human rights and the necessary services to people living with mental illness. Legal initiatives that enforce people with mental illness receive the same societal rights given to people with physical health conditions are of core necessity. The ethical and human rights challenges faced by mental illness and their families are significant. These include: (1) the stigma attached to mental illness and the discrimination faced by individuals who have mental illness and their families, (2) a lack of public awareness on mental illness and limited knowledge about the underlying pathobiology of mental illness which have perhaps resulted in mental health being overlooked by health providers and the policy makers.

An emphasis will also need to be placed on: (1) further disentangling the vicious link between mental ill-health and poverty, (2) providing easier and more affordable access to high quality primary care mental health services for communities in rural and hard-to-reach areas, (3) developing more adequate mental health policies and implementing the service delivery needed by mental health systems and (4) building the capacity for the inclusion of people with mental illness in development opportunities in their communities. A majority of these initiatives will require attention from development stakeholders in addition to significant economic and political support with an emphasis on prioritizing the right to mental healthcare.

The widespread adoption of policies and practices consistent with a right to mental health services will not only serve to protect people with mental illness from abuse, neglect, and discrimination but will also provide them with the care they desperately need. Such a concerted effort will not only afford people with mental illness a better quality of life but will most importantly allow them to live a more dignified life and in the process dispel the insidious myths that surround mental illness.

\section{Declaration of interest:}

The author reports no conflicts of interest. The author alone is responsible for the content and writing of the paper.

\section{Acknowledgments}

This manuscript is dedicated to Tibuhwa Yafesi Fred Bitanihirwe. I am deeply grateful to Dr. Michelle Karen Funk (WHO) for invaluable intellectual contribution to this manuscript. I also extend my thanks to Dr. Clemente Garcia-Rizo (University of Barcelona), Melissa Harper (WHO), Didier Kadianda M'Baku, Joseph SsaliS sentongo and Tracy Mdl ongwa for providing helpful comments.

\section{References}

1. Hyman SE (2008) A glimmer of light for neuropsychiatric disorders. Nature 455: 890-893.

2. Corrigan PW, Morris SB, Michaels PJ, Rafacz JD, Rüsch N (2012) Challenging the public stigma of mental illness: a meta-analysis of outcome studies. Psychiatr Serv 63: 963-973.
3. Hinshaw SP, Cicchetti D (2000) Stigma and mental disorder: conceptions of illness, public attitudes, personal disclosure, and social policy. Dev Psychopathol 12: 555-598.

4. Hinshaw SP, Stier A (2008) Stigma as related to mental disorders. Annu Rev Clin Psychol 4: 367-393.

5. Drew N, Funk M, Tang S, Lamichhane J, Chávez E, et al. (2011) Human rights violations of people with mental and psychosocial disabilities: an unresolved global crisis. Lancet 378: 1664-1675.

6. Gostin LO, Gable L (2004) The human rights of persons with mental disabilities: a global perspective on the application of human rights principles to mental health. MD Law Rev 63: 20-121.

7. Takagi D, Kondo K, Kawachi I (2013) Social participation and mental health: moderating effects of gender, social role and rurality. BMC Public Health 13: 701.

8. US Department of Health and Human Services (1999) Mental Health: A Report of the Surgeon General. Rockville, MD: US Department of Health and Human Services Administration, Centre for Mental Health Services, National Institutes of Health, National Institute of Mental Health.

9. World Health Organization (2007) Mental health: strengthening mental health promotion. Fact Sheet 220. WHO.

10. World health organization (2012) Risks to Mental Health: An Overview of Vulnerabilities and Risk factors.

11. Preamble to the Constitution of the World Health Organization as adopted by the International Health Conference, New York, 19 June - 22 July 1946; signed on 22 July 1946 by the representatives of 61 States (Official Records of the World Health Organization, no. 2, p. 100).

12. Penedo FJ, Dahn JR (2005) Exercise and well-being: a review of mental and physical health benefits associated with physical activity. Curr Opin Psychiatry 18: 189-193.

13. Richardson CR, Avripas SA, Neal DL, Marcus SM (2005) Increasing lifestyle physical activity in patients with depression or other serious mental illness. J Psychiatr Pract 11: 379-388.

14. Russ TC, Stamatakis E, Hamer M, Starr JM, Kivimäki M, et al. (2012) Association between psychological distress and mortality: individual participant pooled analysis of 10 prospective cohort studies. BMJ 345: e4933.

15. Nordentoft M1, Wahlbeck K, Hällgren J, Westman J, Osby U, et al. (2013) Excess mortality, causes of death and life expectancy in 270,770 patients with recent onset of mental disorders in Denmark, Finland and Sweden. PLoS One 8: e55176.

16. Celano C, Huffman JC (2011) Depression and cardiac disease: a review. Cardiol Rev 19: 130-142.

17. Irwin MR (2007) Depression and risk of cancer progression: an elusive link. J Clin Oncol 25: 2343-2344.

18. World Health Organization (2010) Mental Health and Development: Targeting people with mental health and conditions as a vulnerable group. World Health Organization, Geneva.

19. Saraceno B, van Ommeren M, Batniji R, Cohen A, Gureje O, et al. (2007) Barriers to improvement of mental health services in low-income and middle-income countries. Lancet 370: 1164-1174.

20. The London School of Economics and Political Science (2012) How mental illness loses out in the NHS.

21. World Health Organization (2003) Investing in mental health. Geneva: World Health Organization.

22. World Health Organization (2009) Improving health systems and services for mental health. Geneva: World Health Organization.

23. Goldstein LS1, Dewhirst MW, Repacholi M, Kheifets L (2003) Summary, conclusions and recommendations: adverse temperature levels in the human body. Int J Hyperthermia 19: 373-384.

24. World Health Organization (2013) Mental health action plan 2013-2020. Geneva: World Health Organization.

25. Prince M, Patel V, Saxena S, Maj M, Maselko J, et al. (2007) No health without mental health. Lancet 370: 859-877.

26. World Bank (1993) World development report: investing in health. New York: Oxford University Press Inc. 
Page 9 of 11

27. World Health Organization (2012) Dementia: A public health priority. Geneva: World Health Organization.

28. Morrow RH, Hyder AA, Murray CJ, Lopez AD (1998) Measuring the burden of disease. Lancet 352: 1859-1861.

29. Murray CJ, Lopez AD (1994) Quantifying disability: data, methods and results. Bull World Health Organ 72: 481-494.

30. Murray CJ, Lopez AD, Jamison DT (1994) The global burden of disease in 1990: summary results, sensitivity analysis and future directions. Bull World Health Organ 72: 495-509.

31. Murray CJ, Lopez AD (2013) Measuring the global burden of disease. N Engl J Med 369: 448-457.

32. Whiteford HA, Degenhardt L, Rehm J, Baxter AJ, Ferrari AJ, et al. (2013) Global burden of disease attributable to mental and substance use disorders: findings from the Global Burden of Disease Study 2010. Lancet 382: 1575-1586

33. Bertolote JM, Fleischmann A, De Leo D, Wasserman D (2003) Suicide and mental disorders: do we know enough? Br J Psychiatry 183: 382-383.

34. Nock MK, Hwang I, Sampson NA, Kessler RC (2010) Mental disorders, comorbidity and suicidal behavior: results from the National Comorbidity Survey Replication. Mol Psychiatry 15: 868-876.

35. Nock MK, Borges G, Bromet EJ, Cha CB, Kessler RC, et al. (2008) Suicide and suicidal behavior. Epidemiol Rev 30: 133-154.

36. Hawton K, Saunders KE, O'Connor RC (2012) Self-harm and suicide in adolescents. Lancet 379: 2373-2382.

37. Krug EG, Mercy JA, Dahlberg LL, Zwi AB (2002) The world report on violence and health. Lancet 360: 1083-1088.

38. Mars B, Burrows S, Hjelmeland H, Gunnell D (2014) Suicidal behaviour across the African continent: a review of the literature. BMC Public Health 14: 606 .

39. Nurutdinova D, Chrusciel T, Zeringue A, Scherrer JF, Al-Aly Z, et al. (2012) Mental health disorders and the risk of AIDS-defining illness and death in HIV-infected veterans. AIDS 26: 229-234.

40. World Health Organization (WHO) 2008. HIV/AIDS and mental health.

41. Ruel TD, Boivin MJ, Boal HE, Bangirana P, Charlebois E, et al. (2012) Neurocognitive and motor deficits in HIV-infected Ugandan children with high CD4 cell counts. Clin Infect Dis 54: 1001-1009.

42. Cournos F, McKinnon K, Sullivan G (2005) Schizophrenia and comorbid human immunodeficiency virus or hepatitis C virus. J Clin Psychiatry 66 Suppl 6: 27-33.

43. Patel V (2007) Mental health in low- and middle-income countries. Br Med Bull 81-82: 81-96.

44. Bloom DE, Cafiero ET, Jane-Llopis E, Abrahams-Gessel S, Bloom LR, et al. (2011) The Global Economic Burden of Noncommunicable Diseases. Geneva: World Economic Forum.

45. Gureje O, Jenkins R (2007) Mental health in development: reemphasising the link. Lancet 369: 447-449.

46. United Nations (2000) United Nations Millennium Declaration: Resolution adopted by the general assembly (No. A/RES/55/2 (8th plenary meeting) New York: United Nations General Assembly.

47. Dewa CS, Lin E (2000) Chronic physical illness, psychiatric disorder and disability in the workplace. Soc Sci Med 51: 41-50.

48. Insel TR (2008) Assessing the economic costs of serious mental illness. Am J Psychiatry 165: 663-665.

49. Patra J, Popova S, Rehm J, Bondy S, Flint R et al.(2007) Economic Cost of Chronic Disease in Canada 1995-2003. Ontario: Ontario Chronic Disease Prevention Alliance and the Ontario Public Health Association.

50. Olesen J, Gustavsson A, Svensson M, Wittchen HU, Jönsson B; CDBE2010 study group; European Brain Council (2012) The economic cost of brain disorders in Europe. Eur J Neurol 19: 155-162.

51. Centre for Mental Health (2010) The economic and social costs of mental health problems in 2009/10

52. Australian Bureau of Statistics 2009: Adult collaborative Mental Health Care- Final Report.
53. Kessler RC, Little RJ, Groves RM (1995) Advances in strategies for minimizing and adjusting for survey nonresponse. Epidemiol Rev 17: 192-204.

54. World Health Organization (WHO): Mental Health Atlas 2011. Geneva: WHO Press.

55. Patel V, Araya R, Chatterjee S, Chisholm D, Cohen A, et al. (2007) Treatment and prevention of mental disorders in low-income and middle-income countries. Lancet 370: 991-1005.

56. Chisholm D, Saxena S (2012) Cost effectiveness of strategies to combat neuropsychiatric conditions in sub-Saharan Africa and South East Asia: mathematical modelling study. BMJ 344: e609.

57. Chisholm D, Lund C, Saxena S (2007) Cost of scaling up mental healthcare in low- and middle-income countries. Br J Psychiatry 191: 528-535.

58. Kessler RC, Demler O, Frank RG, Olfson M, Pincus HA, et al. (2005) Prevalence and treatment of mental disorders, 1990 to 2003. N Engl J Med 352: 2515-2523.

59. WHO (2008) Mental Health Gap Action Programme: scaling up care for mental, neurological and substance use disorders. Geneva: World Health Organization.

60. Rihmer Z (2007) Suicide risk in mood disorders. Curr Opin Psychiatry 20: $17-22$.

61. Eaton J, McCay L, Semrau M, Chatterjee S, Baingana F, et al. (2011) Scale up of services for mental health in low-income and middle-income countries. Lancet 378: 1592-1603.

62. Saraceno B, Dua T (2009) Global mental health: the role of psychiatry. Eur Arch Psychiatry Clin Neurosci 259 Suppl 2: S109-117.

63. Quinn N, Knifton L (2014) Beliefs, stigma and discrimination associated with mental health problems in Uganda: implications for theory and practice. Int J Soc Psychiatry 60: 554-561.

64. Boutté MI (1987) 'The stumbling disease': a case study of stigma among Azorean-Portuguese. Soc Sci Med 24: 209-217.

65. Larson JE1, Corrigan P (2008) The stigma of families with mental illness. Acad Psychiatry 32: 87-91.

66. Corrigan PW, Liberman RP, Engel JD (1990) From noncompliance to collaboration in the treatment of schizophrenia. Hosp Community Psychiatry 41: 1203-1211.

67. Mohit A (2001) Mental health and psychiatry in the Middle East: historical development. East Mediterr Health J 7: 336-347.

68. Patel V, Musara T, Butau T, Maramba P, Fuyane S (1995) Concepts of mental illness and medical pluralism in Harare. Psychol Med 25: 485-493.

69. Ciftci A, Corrigan P (2013) Mental health stigma in the Muslim community. Journal of Muslim Mental Health 7.

70. Roberts LW (2010) Stigma, hope, and challenge in psychiatry: trainee perspectives from five countries on four continents. Acad Psychiatry 34 : $1-4$

71. Aghukwa CN (2010) Medical students' beliefs and attitudes toward mental illness: effects of a psychiatric education. Acad Psychiatry 34: 67-69.

72. Roberts LW, Bandstra BS (2012) Addressing stigma to strengthen psychiatric education. Acad Psychiatry 36: 347-350.

73. Byrne P (2000) Stigma of mental illness and ways of diminishing it. Advances in Psychiatric Treatment 6: 65 -72.

74. Clement S, van Nieuwenhuizen A, Kassam A, Flach C, Lazarus A, et al. (2012) Filmed v. live social contact interventions to reduce stigma: randomised controlled trial. Br J Psychiatry 201: 57-64.

75. Corrigan PW, Rao D (2012) On the self-stigma of mental illness: stages, disclosure, and strategies for change. Can J Psychiatry 57: 464-469.

76. Penn DL, Couture SM (2002) Strategies for reducing stigma toward persons with mental illness. World Psychiatry 1: 20-21.

77. Saxena S, Thornicroft G, Knapp M, Whiteford H (2007) Resources for mental health: scarcity, inequity, and inefficiency. Lancet 370: 878-889. 
Page 10 of 11

78. Kakuma R, Minas H, van Ginneken N, Dal Poz MR, Desiraju K, et al. (2011) Human resources for mental health care: current situation and strategies for action. Lancet 378: 1654-1663.

79. Mate KS, Sifrim ZK, Chalkidou K, Cluzeau F, Cutler D, et al. (2013) Improving health system quality in low- and middle-income countries that are expanding health coverage: a framework for insurance. Int J Qual Health Care 25: 497-504.

80. WHO (2007) Ten Statistical highlights in global public health (Part1): World Health Statistics. Geneva: World Health Organization.

81. Ngui EM1, Khasakhala L, Ndetei D, Roberts LW (2010) Mental disorders, health inequalities and ethics: A global perspective. Int Rev Psychiatry 22: 235-244.

82. Njenga F (2002) Focus on psychiatry in East Africa. Br J Psychiatry 181: 354-359.

83. Roberts LW, Johnson ME, Brems C, Warner TD (2007) Ethical disparities: Challenges encountered by multi-disciplinary providers in fulfilling ethical standards in the care of rural and minority people. Journal of Rural Health 2: 89-97.

84. Ndetei D, Mutiso V, Khasakhala L and Kokonya D (2007) The challenges of human resources in mental health in Kenya. South African Psychiatric Review 10: 33-36.

85. Connell J, Zurn P, Stilwell B, Awases M, Braichet JM (2007) Sub-Saharan Africa: beyond the health worker migration crisis? Soc Sci Med 64: 1876-1891.

86. Beals J, Novins DK, Whitesell NR, Spicer P, Mitchell CM, et al. (2005) Prevalence of mental disorders and utilization of mental health services in two American Indian reservation populations: Mental health disparities in a national context. American Journal of Psychiatry, 162: 1723-1732.

87. Sorsdahl K, Stein DJ, Grimsrud A, Seedat S, Flisher AJ, et al. (2009) Traditional healers in the treatment of common mental disorders in South Africa. J Nerv Ment Dis 197: 434-441.

88. Peltzer K (1999) Faith Healing for Mental and Social Disorders in the Northern Province (South Africa). Journal of Religion in Africa. 3: 387-402.

89. Agara AJ, Makanjuola AB, Morakinyo O (2008) Management of perceived mental health problems by spiritual healers: a Nigerian study. Afr J Psychiatry (Johannesbg) 11: 113-118.

90. Kuruvilla A1, Jacob KS (2007) Poverty, social stress \& mental health. Indian J Med Res 126: 273-278.

91. Patel V, Kleinman A (2003) Poverty and common mental disorders in developing countries. Bull World Health Organ 81: 609-615.

92. Lund C, De Silva M, Plagerson S, Cooper S, Chisholm D, et al. (2011) Poverty and mental disorders: breaking the cycle in low-income and middle-income countries. Lancet 378: 1502-1514.

93. Weich S, Lewis G (1998) Poverty, unemployment, and common mental disorders: population based cohort study. BMJ 317: 115-119.

94. Murali V, Oyebode F (2004) Poverty, social inequality and mental health. Advances in Psychiatric Treatment 10: 216-224.

95. Eaton WW, Muntaner C (1999) "Socioeconomic Stratification and Mental Disorder," in A Handbook for the Study of Mental Health: Social Context, Theories and Systems, ed. Allan V. Horwitz and Teresa L. Scheid New York: Cambridge University Press, 1999: 275-277.

96. Vega WA, Rumbaut RG (1991) Ethnic minorities and mental health. Annual Review of Sociology 17: 351-383.

97. Busfield J (2000) 'Introduction: Rethinking the Sociology of Mental Health', Sociology of Health and Illness 22: 543-558. Oxford: Blackwell Publishers Ltd.

98. Hansson E, Tuck A, Lurie S, McKenzie K (2010) for the Task Group of the Services Systems Advisory Committee, Mental Health Commission of Canada. Improving mental health services for immigrant, refugee, ethnocultural and racialized groups: issues and options for service improvement [Internet]. Calgary (AB): Mental Health Commission of Canada.
99. Kirmayer LJ, Groleau D, Guzder J, Blake C, Jarvis E (2003) Cultural consultation: a model of mental health service for multicultural societies. Can J Psychiatry 48: 145-153.

100. McKenzie K (2012) Commentary: When in Rome? Integration and the rates of mental illness in black and minority ethnic youth. Int J Epidemiol 41: 802-804.

101. Shah J, Mizrahi R, McKenzie K (2011) The four dimensions: a model for the social aetiology of psychosis. Br J Psychiatry 199: 11-14.

102. McKenzie K (2008) Improving mental healthcare for ethnic minorities. Advances in Psychiatric Treatment 14: 285-291.

103. Bhugra D, Jones P (2001) Migration and mental illness. Advances in Psychiatric Treatment 7: 216-22.

104. International Organization for Migration (IOM) (2010) Psychosocial Needs Assessment in Emergency Displacement, Early Recovery, and Return. IOM Tools. International Organization for Migration, Geneva.

105. Bhui K, Warfa N, Edonya P, McKenzie K, Bhugra D (2007) Cultural competence in mental health care: a review of model evaluations. BMC Health Serv Res 7: 15.

106. Moffat J1, Sass B, McKenzie K, Bhui K (2009) Enhancing pathways \& mental healthcare for BME groups: learning between the ideological and operational. Int Rev Psychiatry 21: 450-459.

107. Moffat J1, Sass B, McKenzie K, Bhui K (2009) Improving pathways into mental health care for black and ethnic minority groups: a systematic review of the grey literature. Int Rev Psychiatry 21: 439-449.

108. Ziguras SJ, Stankovska M, Minas IH (1999) Initiatives for improving mental health services to ethnic minorities in Australia. Psychiatr Serv 50: 1229-1231.

109. Kouyoumdjian H, Zamboanga BL, Hansen DJ (2003) Barriers to community mental health services for Latinos: Treatment considerations. Clinical Psychology: Science and Practice 10: 394-422.

110. United Nations. The Universal Declaration of Human Rights.

111. WHO/WONCA (2008) Integrating Mental Health into Primary Care: A Global Perspective. World Health Organization and World Organization of Family Doctors (WONCA), Geneva

112. Funk M, Saraceno B, Drew N, Faydi E (2008) Integrating mental health into primary healthcare. Ment Health Fam Med 5: 5-8.

113. Patel V, Belkin GS, Chockalingam A, Cooper J, Saxena S, et al. (2013) Grand challenges: integrating mental health services into priority health care platforms. PLoS Med 10: e1001448.

114. Baumgartner JN, Susser E (2013) Social integration in global mental health: what is it and how can it be measured? Epidemiol Psychiatr Sci 22: 29-37.

115. Lal S, Adair CE (2014) E-mental health: a rapid review of the literature. Psychiatr Serv 65: 24-32.

116. Postel MG, de Haan HA, Ter Huurne ED, Becker ES, de Jong CA (2011) Characteristics of problem drinkers in e-therapy versus face-to-face treatment. Am J Drug Alcohol Abuse 37: 537-542.

117. Knaevelsrud C, Maercker A (2007) Internet-based treatment for PTSD reduces distress and facilitates the development of a strong therapeutic alliance: a randomized controlled clinical trial. BMC Psychiatry 7: 13.

118. World Health Organization (2011) mHealth: New horizons for health through mobile technologies. Geneva: World Health Organization.

119. Catalani C1, Philbrick W, Fraser H, Mechael P, Israelski DM (2013) mHealth for HIV Treatment \& Prevention: A Systematic Review of the Literature. Open AIDS J 7: 17-41.

120. Doku VC, Wusu-Takyi A, Awakame J (2012) Implementing the Mental Health Act in Ghana: any challenges ahead? Ghana Med J 46: 241-250.

121. Epping-Jordan JE (2005) Integrated approaches to prevention and control of chronic conditions. Kidney Int Suppl : S86-88.

122. Chisholm D, Lund C, Saxena S (2007) Cost of scaling up mental healthcare in low- and middle-income countries. Br J Psychiatry 191: 528-535.

123. Patel V, Araya R, Chatterjee S, Chisholm D, Cohen A, et al. (2007) Treatment and prevention of mental disorders in low-income and middle-income countries. Lancet 370: 991-1005. 
Page 11 of 11

124. Patel V, Simon G, Chowdhary N, Kaaya S, Araya R (2009) Packages of care for depression in low- and middle-income countries. PLoS Med 6: e1000159.

125. Tol WA, Barbui C, Galappatti A, Silove D, Betancourt TS, et al. (2011) Mental health and psychosocial support in humanitarian settings: linking practice and research. Lancet 378: 1581-1591.

126. Chisholm D (2006) Dollars, DALYs and Decisions: Economic Aspects of the Mental Health System. Geneva: World Health Organization.

127. World Health Organization (2003) Advocacy for Mental Health: Targeting people with mental health and conditions as a vulnerable group. World Health Organization, Geneva.

128. World Health Organization (2005) Mental Health Policy, Plans and Programmes: Targeting people with mental health and conditions as a vulnerable group. World Health Organization, Geneva.

129. Eaton J, McCay L, Semrau M, Chatterjee S, Baingana F, et al. (2011) Scale up of services for mental health in low-income and middle-income countries. Lancet 378: 1592-1603.
130. Moussavi S, Chatterji S, Verdes E, Tandon A, Patel V, et al. (2007) Depression, chronic diseases, and decrements in health: results from the World Health Surveys. Lancet 370: 851-858.

131. Scott D, Happell B (2011) The high prevalence of poor physical health and unhealthy lifestyle behaviours in individuals with severe mental illness. Issues Ment Health Nurs 32: 589-597.

132. Ngo VK, Rubinstein A, Ganju V, Kanellis P, Loza N, et al. (2013) Grand challenges: Integrating mental health care into the non-communicable disease agenda. PLoS Med 10: e1001443.

133. Andrews G, Issakidis C, Sanderson K, Corry J, Lapsley H (2004) Utilising survey data to inform public policy: comparison of the cost-effectiveness of treatment of ten mental disorders. Br J Psychiatry 184: 526-533.

134. Drew N, Funk M, Kim C, Lund C, Flischer AJ, et al. (2013) Mental health law in Africa: analysis from a human rights perspective, Journal of Public Mental Health 2: 1 -20. 